\title{
Validation of the EORTC-QLQ-HN35 Questionnaire in Turkish Head and Neck Cancer Patients
}

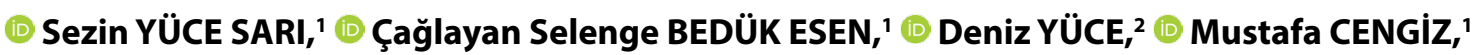 \\ (1) Gökhan ÖZYiĞiT,' ' (1) Gözde YAZICl'1
}

'Department of Radiation Oncology, Hacettepe University Faculty of Medicine, Ankara-Turkey

${ }^{2}$ Department of Preventive Oncology, Hacettepe University Faculty of Medicine, Ankara-Turkey

\begin{abstract}
OBJECTIVE
To assess the validity and reliability of the EORTC-QLQ-HN35 in Turkish head and neck cancer (HNC) patients.

\section{METHODS}

EORTC QLQ-C30 and QLQ-HN35 scales were completed by patients at the beginning, middle and end of radiotherapy. Internal consistency was assessed by Cronbach alpha and test-retest reliability by intraclass correlation coefficients (ICCs). Content validity was based on expert opinion and patient reviews.

\section{RESULTS}

Eighty patients were included in this study. Mean age was $59 \pm 10.7$ years. Overall internal consistency was satisfactory $(\alpha=0.926)$. Overall test-retest reliability was satisfactory and ICCs ranged between 0.77 and 0.84. Correlations between corresponding domains of QLQ-C30 and HN35 showed satisfactory convergent validity $(r=0.61$ to $r=0.73)$. Assessments based on expert opinions and patient reviews also favored the content validity of the scale.
\end{abstract}

\section{CONCLUSION}

The Turkish version of the QLQ-HN35 scale is a valid and reliable tool to evaluate the health-related quality of life in patients with HNC.

Keywords: Head and neck cancer; quality of life; questionnaire; radiotherapy; validation.

Copyright $\odot$ 2020, Turkish Society for Radiation Oncology

\section{Introduction}

The annual incidence of head and neck cancer (HNC) is approximately 600.000 worldwide.[1] Treatment modalities include surgery and radiotherapy (RT), either alone or combined, with or without chemotherapy (CT). Based on the radiobiologic characteristic of HNC, RT doses are relatively high. The vicinity of the critical organs with low tolerance doses to the target and the common use of concurrent chemoradiother- apy (CRT) in HNC increase the risk of RT-related toxicity.[2] As a result, the quality of life (QoL) deteriorates with progressing weeks of RT.

Many QoL questionnaires have been developed to objectively evaluate the QoL. The most commonly used questionnaire which measures the QoL of patients with HNC is the one developed by the European Organization for the Research and Treatment of Cancer (EORTC), which is called the 'Quality of Life Questionnaire-Head and Neck 35' (QLQ-HN35). QLQ-HN35 
is used together with the 'QLQ-Core30' (QLQ-C30), which assesses the general well-being of patients. The present study aims to validate the use of the QLQ-HN35 in Turkish patients with HNC that underwent RT.

\section{Materials and Methods}

For the validation of the QLQ-HN35 scale in Turkish patients, official approval was obtained from the EORTC. The Turkish translation of the QLQ-HN35 scale was already available from the developers, and the reliability and validity of the scale were assessed during this study.

\section{Study Population}

Eighty HNC patients who were referred to the Radiation Oncology Department of Hacettepe University Medical School for either definitive or adjuvant RT with/without concurrent CT were invited to participate in this study and recruited following their provision of written informed consents. The QLQ-C30 and QLQ-HN35 scales were completed by patients at three-time points as the beginning, middle, and end of the treatment period. After each patient completed answering the questions in both modules, they were also asked about whether any questions in the QLQHN35 module were confusing, upsetting, or difficult to understand. The data collection continued between January 2014 and September 2018. The study protocol was approved by the Hacettepe University Ethics Committee for Non-Invasive Clinical Research.

\section{EORTC QLQ-C30 and HN35 Scales}

EORTC QLQ-C30 measures the general QoL and can be used alone or together with other questionnaires developed for specific anatomic locations. EORTC QLQ-C30 provides a general health status score, also provides scores for symptom and functional domains. On the other hand, the QLQ-HN35 is specific to HNC and provides scores for various symptom domains. The QLQ-HN35 includes 35 questions: 11 single item subscales relating to teeth, opening the mouth, dry mouth, sticky saliva, coughing, feeling ill, pain killers, nutritional supplements, feeding tube, weight gain and weight loss. QLQ-HN35 also includes 24 items grouped into seven subscales as follows: pain (4 items), swallowing ( 4 items), senses problems ( 2 items), speech problems ( 3 items), trouble with social eating ( 4 items), trouble with social contact (5 items), and less sexuality (2 items). The response format was a four-point Likert scale in both QLQ-C30 and QLQ-HN35. Responses to the questionnaires were transformed into a $0-100$ scale using EORTC guidelines.[3] The decrease in scores of general health status and functional scales in EORTC QLQ-C30 imply deterioration of these scales, whereas the increase in scores of symptom scales in both questionnaires implies deterioration of symptoms.

\section{Statistical Analysis}

Descriptive statistics were presented using either mean \pm standard deviation or median [interquartile range] for numerical variables, and frequencies and percent for categorical variables. The comparisons of numerical data between independent groups were performed using the Mann-Whitney $U$ test for two groups, and the Kruskal-Wallis test for more than two groups. The comparisons of numerical data between dependent groups were performed with the Friedman test for more than two groups. Internal consistency was assessed by Cronbach alpha, and test-retest reliability was assessed by intraclass correlation coefficients (ICCs). Construct validity was evaluated by correlation matrices between subdomains of the scale. Discriminant validity was analyzed by comparison of QoL scores between the most common three diagnostic groups. For clinical validity, an absolute change of 10 points on a 0 -100-point score was suggested to be clinically important for the QoL assessments (1-23). Thus, a difference between the preand post-treatment domain scores of QLQ-HN35 was calculated and compared with a reference value of 10 using a one-sample T-test. All statistical analyses were performed with SPSS $25^{\circ}$ (IBM Corp., Armonk, NY, USA) software, with a two-tailed design and a type-I error level of $5 \%$.

\section{Results}

This study included 80 patients who received definitive or adjuvant RT with or without CT for HNC. The mean age of the patients was $59 \pm 10.7$ years, and the majority of them were male. The general demographic and clinical characteristics of the patients are presented in Table 1.

The attrition rates were $1.3 \%(n=1)$ and $18.8 \%(n=15)$ at treatment onset and end-of-treatment assessments, respectively. The primary reason for high attrition at the end of the treatment was a refusal to complete the questionnaire due to the completion of the RT.

The analyses for treatment-related changes in clinical parameters revealed that the grade of mucositis $(\mathrm{p}<0.001)$ and pain score $(\mathrm{p}<0.001)$ significantly increased, and mean body weight significantly decreased $(\mathrm{p}<0.001) \quad$ (Table 2, Fig. 1). For the health-related 


\begin{tabular}{|c|c|}
\hline Characteristic & n (\%) \\
\hline \multicolumn{2}{|l|}{ Gender } \\
\hline Female & $23(29)$ \\
\hline Male & $57(71)$ \\
\hline \multicolumn{2}{|l|}{ Primary tumor location } \\
\hline Larynx & $25(31)$ \\
\hline Nasopharynx & $23(29)$ \\
\hline Oral cavity & $14(18)$ \\
\hline Hypopharynx & $5(6)$ \\
\hline Paranasal sinus & $4(5)$ \\
\hline Salivary gland & $4(5)$ \\
\hline Unknown primary & $3(4)$ \\
\hline Oropharynx & $1(1)$ \\
\hline Skin & $1(1)$ \\
\hline \multicolumn{2}{|l|}{ T stage } \\
\hline T0 & $4(5)$ \\
\hline T1 & $17(21)$ \\
\hline $\mathrm{T} 2$ & $24(30)$ \\
\hline $\mathrm{T} 3$ & $20(25)$ \\
\hline T4 & $15(19)$ \\
\hline \multicolumn{2}{|l|}{ N stage } \\
\hline No & $33(41)$ \\
\hline N1 & $13(16)$ \\
\hline N2 & $19(24)$ \\
\hline N3 & $15(19)$ \\
\hline \multicolumn{2}{|c|}{ Concurrent chemotherapy } \\
\hline Yes & $59(74)$ \\
\hline No & $21(26)$ \\
\hline \multicolumn{2}{|l|}{ Surgery } \\
\hline Yes & 31 (39) \\
\hline No & $49(61)$ \\
\hline
\end{tabular}

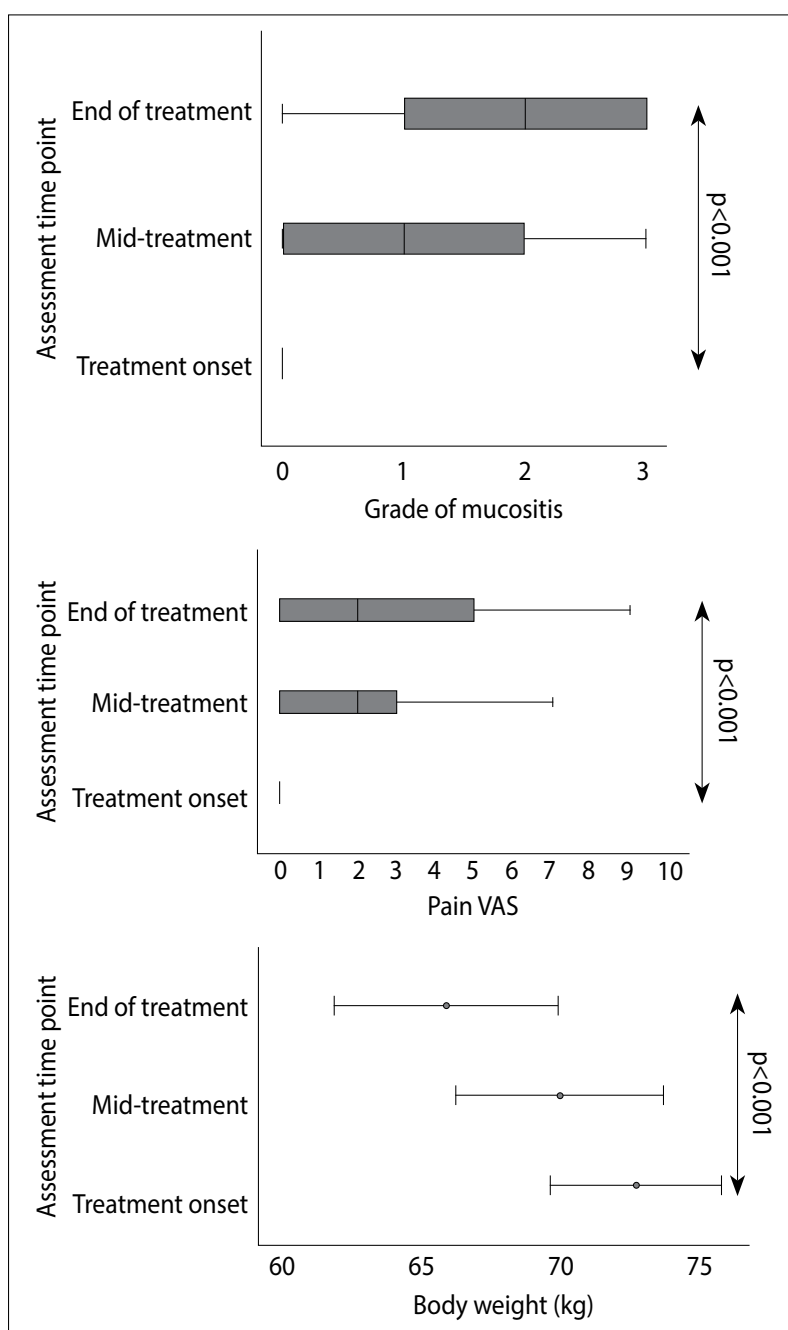

Fig. 1. Changes in the treatment-related clinical parameters during the treatment.

Table 2 Changes in the treatment-related clinical parameters during the treatment

\begin{tabular}{|c|c|c|c|c|}
\hline & $\begin{array}{c}\text { Treatment onset } \\
\text { n (\%) }\end{array}$ & $\begin{array}{c}\text { Mid-treatment } \\
\text { n (\%) }\end{array}$ & $\begin{array}{c}\text { End of treatment } \\
\qquad \mathbf{n}(\%)\end{array}$ & $\mathbf{p}$ \\
\hline Grade of mu & & & & $<0.001$ \\
\hline Grade 0 & $74(92.5)$ & $32(40.5)$ & $12(18.5)$ & \\
\hline Grade 1 & $3(3.8)$ & $28(35.4)$ & $20(30.8)$ & \\
\hline Grade 2 & $1(1.3)$ & $16(20.3)$ & $15(23.1)$ & \\
\hline \multirow[t]{2}{*}{ Grade 3} & $2(2.5)$ & $3(3.8)$ & $18(27.7)$ & \\
\hline & Median [IQR] & Median [IQR] & Median [IQR] & \\
\hline \multirow[t]{2}{*}{ Pain VAS } & $0[0-0]$ & $2[0-3]$ & $2[0-5]$ & $<0.001$ \\
\hline & Mean SD & Mean \pm SD & Mean \pm SD & \\
\hline Weight (kg) & $72.7 \pm 12.9$ & $69.9 \pm 14.9$ & $65.9 \pm 16.2$ & $<0.001$ \\
\hline
\end{tabular}

VAS: Visual analog scale; IQR: Interquartile range; SD: Standard deviation 
QoL assessments, dyspnea and diarrhea scores in the QLQ-C30 scale, and the teeth, pain killer, nutritional supplements, and feeding tube scores in the QLQ-HN35 scale did not change significantly during the treatment period. The remaining symptom scores in both scales generally increased during the treatment period. On the other hand, functional scales of QLQ-C30 decreased during the treatment period (Table 3 ).

Overall internal consistency of QLQ-HN35 was excellent at each assessment period (treatment on- set $\alpha=0.926$, mid-treatment $\alpha=0.937$, end of treatment $\alpha=0.944)$. Overall test-retest reliability was satisfactory and ICCs ranged between 0.77 and 0.84 . Correlations between corresponding domains of QLQ-C30 and QLQ-HN35 showed satisfactory convergent validity $(r=0.61$ to $r=0.73)$. Comparisons of the QLQ-HN35 scores between the most common three diagnostic groups concerning divergent validity showed that the differences among the symptom scores were compatible between the diagnosis and clinical behavior. The clinical

Table 3 Changes in the QoL assess nebts during the study period

\begin{tabular}{|c|c|c|c|c|}
\hline & $\begin{array}{c}\text { Treatment onset } \\
\text { Median [IQR] }\end{array}$ & $\begin{array}{c}\text { Mid-treatment } \\
\text { Median [IQR] }\end{array}$ & $\begin{array}{l}\text { End of treatment } \\
\text { Median [IQR] }\end{array}$ & $\mathbf{p}$ \\
\hline \multicolumn{5}{|l|}{ EORTC-QLQ-C30 } \\
\hline Global health status/QoL & $66.7[58.3-83.3]$ & $58.3[41.7-75]$ & $50[33.3-66.7]$ & $<0.001$ \\
\hline \multicolumn{5}{|l|}{ Functional scales } \\
\hline Physical functioning & 86.7 [70-93.3] & $80[60-86.7]$ & $73.3[46.7-86.7]$ & $<0.001$ \\
\hline Role functioning & $100[83.3-100]$ & $83.3[66.7-100]$ & $66.7[33.3-100]$ & $<0.001$ \\
\hline Emotional functioning & $83.3[66.7-100]$ & $83.3[66.7-91.7]$ & 75 [58.3-91.7] & 0.013 \\
\hline Cognitive functioning & $83.3[75-100]$ & $83.3[66.7-100]$ & $83.3[66.7-100]$ & 0.003 \\
\hline Social functioning & $91.7[66.7-100]$ & $83.3[66.7-100]$ & $66.7[33.3-100]$ & 0.001 \\
\hline \multicolumn{5}{|l|}{ Symptom scales } \\
\hline Fatigue & $33.3[11.1-44.4]$ & $33.3[33.3-55.6]$ & $44.4[33.3-66.7]$ & $<0.001$ \\
\hline Nausea and vomiting & $0[0-16.7]$ & $16.7[0-33.3]$ & $33.3[16.7-66.7]$ & $<0.001$ \\
\hline Pain & $16.7[0-33.3]$ & 16.7 [16.7-33.3] & $33.3[16.7-66.7]$ & $<0.001$ \\
\hline Dyspnea & $0[0-33.3]$ & $0[0-33.3]$ & $0[0-33.3]$ & 0.764 \\
\hline Insomnia & $16.7[0-33.3]$ & $0[0-33.3]$ & $33.3[0-33.3]$ & $<0.001$ \\
\hline Appetite loss & $0[0-33.3]$ & $33.3[33.3-66.7]$ & $66.7[33.3-100]$ & $<0.001$ \\
\hline Constipation & $0[0-33.3]$ & $33.3[0-33.3]$ & $33.3[0-66.7]$ & $<0.001$ \\
\hline Diarrhea & $0[0-0]$ & $0[0-0]$ & $0[0-0]$ & 0.237 \\
\hline Financial difficulties & $33.3[0-50]$ & $33.3[0-66.7]$ & $33.3[0-66.7]$ & 0.015 \\
\hline \multicolumn{5}{|l|}{ EORTC-QLQ-HN35 } \\
\hline Pain & $16.7[0-25]$ & $33.3[16.7-50]$ & $41.7[33.3-66.7]$ & $<0.001$ \\
\hline Swallowing & $0[0-25]$ & $25[8.3-41.7]$ & $41.7[16.7-58.3]$ & $<0.001$ \\
\hline Senses problems & $0[0-33.3]$ & $33.3[16.7-50]$ & $50[33.3-66.7]$ & $<0.001$ \\
\hline Speech problems & $11.1[0-33.3]$ & $22.2[0-44.4]$ & $33.3[11.1-55.6]$ & $<0.001$ \\
\hline Trouble with social eating & $8.3[0-25]$ & $25[8.3-50]$ & $41.7[25-58.3]$ & $<0.001$ \\
\hline Trouble with social contact & $6.7[0-20]$ & $6.7[0-33.3]$ & $20[6.7-53.3]$ & $<0.001$ \\
\hline Less sexuality & $16.7[0-33.3]$ & $33.3[0-33.3]$ & $33.3[0-83.3]$ & $<0.001$ \\
\hline Teeth & $0[0-33.3]$ & $0[0-33.3]$ & $0[0-33.3]$ & 0.309 \\
\hline Opening mouth & $0[0-33.3]$ & $33.3[0-33.3]$ & $33.3[0-66.7]$ & 0.001 \\
\hline Dry mouth & $33.3[0-33.3]$ & $33.3[33.3-66.7]$ & $66.7[33.3-100]$ & $<0.001$ \\
\hline Sticky saliva & $0[0-33.3]$ & $33.3[33.3-66.7]$ & $66.7[33.3-100]$ & $<0.001$ \\
\hline Coughing & $0[0-33.3]$ & $33.3[0-33.3]$ & $33.3[0-66.7]$ & $<0.001$ \\
\hline Felt ill & $33.3[0-33.3]$ & $33.3[0-66.7]$ & $33.3[33.3-66.7]$ & $<0.001$ \\
\hline Pain killers & $0[0-100]$ & $100[0-100]$ & $0[0-100]$ & 0.38 \\
\hline Nutritional supplements & $100[0-100]$ & $100[100-100]$ & $100[0-100]$ & 0.25 \\
\hline Feeding tube & 100 [100-100] & $100[100-100]$ & $100[100-100]$ & 0.155 \\
\hline Weight loss & $100[0-100]$ & $0[0-100]$ & $0[0-0]$ & $<0.001$ \\
\hline Weight gain & $100[0-100]$ & $100[100-100]$ & $100[100-100]$ & $<0.001$ \\
\hline
\end{tabular}

QoL: Quality of life; IQR: Interquartile range 
Table 4 Clinically significant changes in the QLQ-HN35 scale scores during the treatment

\begin{tabular}{|c|c|c|c|c|}
\hline & \multicolumn{4}{|c|}{ Absolute change during treatment } \\
\hline & Mean & SD & $\begin{array}{c}\text { Mean difference } \\
\text { (test value }=10 \text { ) }\end{array}$ & $\mathbf{p}$ \\
\hline Pain & 31.9 & 22.6 & 21.9 & $<0.001$ \\
\hline Swallowing & 29.4 & 26.9 & 19.4 & $<0.001$ \\
\hline Senses problems & 37.4 & 24.1 & 27.4 & $<0.001$ \\
\hline Speech problems & 21.2 & 20.5 & 11.2 & $<0.001$ \\
\hline Trouble with social eating & 31.4 & 23.3 & 21.4 & $<0.001$ \\
\hline Trouble with social contact & 19.6 & 21.1 & 9.6 & 0.001 \\
\hline Less sexuality & 24.1 & 28.9 & 14.1 & $<0.001$ \\
\hline Teeth & 18.5 & 26.4 & 8.5 & 0.012 \\
\hline Opening mouth & 27.2 & 26.9 & 17.2 & $<0.001$ \\
\hline Dry mouth & 37.9 & 28.8 & 27.9 & $<0.001$ \\
\hline Sticky saliva & 44.1 & 34.9 & 34.1 & $<0.001$ \\
\hline Coughing & 25.6 & 24.1 & 15.6 & $<0.001$ \\
\hline Felt ill & 30.3 & 24.1 & 20.3 & $<0.001$ \\
\hline Pain killers & 38.5 & 49.0 & 28.5 & $<0.001$ \\
\hline Nutritional supplements & 35.4 & 48.2 & 25.4 & $<0.001$ \\
\hline Feeding tube & 21.5 & 41.4 & 11.5 & 0.028 \\
\hline Weight loss & 55.4 & 50.1 & 45.4 & $<0.001$ \\
\hline Weight gain & 44.6 & 50.1 & 34.6 & $<0.001$ \\
\hline
\end{tabular}

SD: Standard deviation

validity was assessed by comparing the absolute changes between treatment onset and end-of-treatment with a reference value of 10 , and all domains showed statistically significant clinical changes (Table 4).

\section{Discussion}

In the present study, the validity and reliability of the Turkish version of QLQ-HN35 was evaluated in a sample of 80 patients with HNC, and based on our results, the Turkish version of QLQ-HN35 was found to be a valid and reliable tool to evaluate health-related QoL in patients with HNC that underwent RT with or without CT.

The EORTC QLQ-HN35 was developed by Bjordal et al. to measure the QoL in patients with HNC and the pre-testing was performed in patients from Norway, Sweden, Denmark, United Kingdom and Belgium.[4] In 1999, a preliminary reliability and validity study was performed in 500 patients from Norway, Sweden and the Netherlands during and after treatment which resulted in proposal of additional questions based on the feedback of the patients.[5] They reported the Cronbach's alpha coefficient $\geq 0.78$ in all samples and the compliance rate as $83 \%$. In 2000 , a cross-validation study approved the reliability of the QLQ-HN35 module in patients with advanced HNC.[6] In the same year, Bjordal et al. published the final clinical validity of scales and single items and results on psychometric properties of the QLQ-H\&N35 in patients from 12 countries speaking nine languages.[7] This study included 622 patients under treatment for the first time or for the recurrent disease that underwent surgery and/or RT and/or CT, and also disease-free patients 1-3.5 years after treatment. The rate of unanswered questions was $<3 \%$ in this study, and they reported the Cronbach's alpha coefficient $>0.70$ for all scales but the senses scale in patients with pharyngeal cancer, which was found 0.68 .

In the following years, validation of the QLQ-HN35 module in several more languages has been performed in patients with $\mathrm{HNC}$ of different sites undergoing different treatment modalities or under follow-up. In 2013, Singer at al. reviewed 136 studies in 19 different languages in 27 countries. [8] They reported that the scales of sexuality and speech were the scales with the highest percentages of missing values. They found that the median Cronbach's alpha was between 0.61 and 0.93. The authors also published their results in patients that received targeted or multimodal therapy for 
HNC and detected some deficiency in the QLQ-HN35 module regarding the toxicity of these therapeutic options, such as rash, nail changes, pulmonary symptoms and impairment of fertility, and proposed an update of the module.[9] This study led the way to the development of the QLQ-HN43 module. Our next aim is to validate this updated version in Turkish HNC patients.

\section{Limitations}

A higher number of patients in the present study could have resulted in a more accurate statistical analysis. In addition, although the attrition rate was satisfactory at the beginning of the treatment, the attrition rate increased to $18.8 \%$ at the end. A lower rate of attrition at the end could have also yielded different statistical results.

\section{Conclusion}

The present study reveals that the Turkish version of the EORTC QLQ-HNC can be used to assess the QoL in patients with HNC. The questionnaire is validated in both genders and all stages of HNCs.

Peer-review: Externally peer-reviewed.

Conflict of Interest: The authors declare that they have no conflict of interest.

Ethics Committee Approval: The study protocol was approved by the Hacettepe University Ethics Committee for Non-Invasive Clinical Research.

Financial Support: None declared.

Authorship contributions: Concept - G.Y., M.C., G.Ö.; Design - G.Y., S.Y.S., C.S.B.E.; Supervision - G.Y., M.C., G.Ö.; Funding - None; Materials - G.Y., Ç.S.B.E.; Data collection and/or processing - S.Y.S., C.S.B.E.; Data analysis and/or interpretation - G.Y., Ç.S.B.E., S.Y.S., D.Y.; Literature search - S.Y.S., G.Y.; Writing - S.Y.S., Ç.S.B.E., D.Y., G.Y., M.C., G.Ö.; Critical review - G.Y., M.C., G.Ö.

\section{References}

1. Brizel DM, Geiger JL. Locally Advanced Squamous Carcinoma of the Head and Neck. In: Halperin EC, Wazer DE, Perez CA, Brady LW, editors. Principles and Practice of Radiation Oncology. 7th ed. Philadelphia: Wolters Kluver; 2019. p. 2796-841.

2. Lok BH, Leeman JE, Lee NY. Nasopharynx. In: Halperin EC, Wazer DE, Perez CA, Brady LW, editors. Principles and Practice of Radiation Oncology. $7^{\text {th }}$ ed. Philadelphia: Wolters Kluver; 2019. p. 2842-951.

3. Fayers P, Aaronson NK, Bjordal K, Groenvold M, Curran D, Bottomley A. EORTC QLQ-C30 Scoring Manual. 3rd ed. Brussels: European Organisation for Research and Treatment of Cancer; 2001.

4. Bjordal K, Ahlner-Elmqvist M, Tollesson E, Jensen AB, Razavi D, Maher EJ, et al. Development of a European Organization for Research and Treatment of Cancer (EORTC) questionnaire module to be used in quality of life assessments in head and neck cancer patients. EORTC Quality of Life Study Group. Acta Oncol 1994;33(8):879-85.

5. Bjordal K, Hammerlid E, Ahlner-Elmqvist M, de Graeff A, Boysen M, Evensen JF, et al. Quality of life in head and neck cancer patients: validation of the European Organization for Research and Treatment of Cancer Quality of Life Questionnaire-H\&N35. J Clin Oncol 1999;17(3):1008-19.

6. Sherman AC, Simonton S, Adams DC, Vural E, Owens B, Hanna E. Assessing quality of life in patients with head and neck cancer: cross-validation of the European Organization for Research and Treatment of Cancer (EORTC) Quality of Life Head and Neck module (QLQ-H\&N35). Arch Otolaryngol Head Neck Surg 2000;126(4):459-67.

7. Bjordal K, de Graeff A, Fayers PM, Hammerlid E, van Pottelsberghe C, Curran D, et al. A 12 country field study of the EORTC QLQ-C30 (version 3.0) and the head and neck cancer specific module (EORTC QLQH\&N35) in head and neck patients. EORTC Quality of Life Group. Eur J Cancer 2000;36(14):1796-807.

8. Singer S, Arraras JI, Chie WC, Fisher SE, Galalae $\mathrm{R}$, Hammerlid E, et al. Performance of the EORTC questionnaire for the assessment of quality of life in head and neck cancer patients EORTC QLQH\&N35: a methodological review. Qual Life Res 2013;22(8):1927-41.

9. Singer S, Arraras JI, Baumann I, Boehm A, Chie WC, Galalae R, et al. Quality of life in patients with head and neck cancer receiving targeted or multimodal therapy--update of the EORTC QLQ-H\&N35, Phase I. Head Neck 2013;35(9):1331-8. 